\title{
Tecnologías de información y comunicación en la Agencia Estatal de
}

\section{Administración Tributaria}

Manuel Javier Cabrera Pardo

Delegado especial de la AEAT en la Comunitat Valenciana

Agencia Estatal de Administración Tributaria

\section{Resumen}

La Agencia Tributaria viene desarrollando una estrategia de posicionamiento en la vanguardia del uso de las nuevas tecnologías. Actualmente, este proceso de digitalización de la Administración Tributaria ha recibido un nuevo impulso a través del Plan Estratégico de la AEAT para el periodo 2020-2023 y del Plan de Recuperación, Transformación y Resiliencia presentado por España a la Unión Europea en 2021. La Administración tributaria está llevando a cabo la implantación de diversas medidas al objeto de adaptarse de manera ágil y eficaz a las nuevas demandas de un entorno digital cambiante. Ello orientado a impulsar el cumplimiento voluntario de las obligaciones tributarias y la prevención y control del fraude tributario. Se generan nuevas formas de relación con los contribuyentes como son la nueva Administración Digital Integral, la acreditación mediante video-asistencia o las notificaciones electrónicas. El análisis y explotación de la información se realiza igualmente aprovechando las oportunidades que proporcionan las nuevas tecnologías de información y comunicación.

\section{La digitalización de la Administración Tributaria}

La Agencia Estatal de Administración Tributaria, como organización que tiene encomendada la aplicación del sistema tributario estatal y del aduanero, desarrolla sus actuaciones en el marco del Plan Estratégico 2020-2023.

El Plan Estratégico define los compromisos, prioridades, líneas de actuación e indicadores de resultados de la Agencia Tributaria, y se configura como un documento abierto en función de nuevas necesidades y prioridades que puedan surgir en un entorno en el que los avances tecnológicos y los nuevos modelos de negocio están produciendo cambios permanentes y acelerados generando, a su vez, nuevos retos y oportunidades para las Administraciones tributarias.

En este punto, cabe destacar que el soporte del Plan Estratégico de la Agencia Tributaria para el período 2020-2023, es esencialmente tecnológico. En concreto, en el plan se contempla como uno de los pilares básicos la potenciación e implantación 
de nuevas medidas dirigidas a evitar o limitar la posibilidad del fraude, actuando con carácter previo incluso a la presentación de las declaraciones tributarias e impulsando medidas que fomenten el cumplimiento voluntario, así como la maximización de la eficacia y la eficiencia de la lucha contra las modalidades de fraude más complejas, gracias a nuevas herramientas que se encuentran a disposición de la Agencia basadas en la utilización de nuevas tecnologías.

En la primera reunión plenaria de la Tax Administration European Union Summit (TADEUS), celebrada en septiembre de 2019, se señalaron como principales retos de las administraciones tributarias, entre otros: la economía digital y la digitalización de las administraciones tributarias.

En resumen, para cumplir su cometido, la Agencia Tributaria se apoya en el uso intensivo en tecnologías de la información, teniendo una reputación contrastada a nivel internacional, como demuestra, a título de ejemplo, el premio "Exhibition of digital transformation initiatives" recibido en la Asamblea General de la IOTA por el proyecto del Suministro Inmediato de Información.

Por otra parte, con al fin de contrarrestar el impacto de la pandemia sobre la inversión y la actividad económica, el Plan de Recuperación, Transformación y Resiliencia, remitido por España a la Unión Europea en abril y aprobado formalmente por Bruselas en junio de 2021, contempla una serie de medidas para impulsar la recuperación y abordar una modernización de la economía española, con el soporte de los créditos previstos en la asignación a España en los nuevos instrumentos comunitarios de financiación Next Generation.

Uno de los ejes de este Plan, en línea con la estrategia digital europea y la Agenda España Digital 2025, fija la hoja de ruta para acelerar una transición digital en España.

En el ámbito de la Administración tributaria, el Plan de Recuperación incorpora, en su Componente 27 "Medidas y actuaciones de prevención y lucha contra el fraude fiscal", un conjunto de medidas articuladas en cinco bloques y orientadas a prevenir $y$, en su caso, luchar contra el fraude fiscal, que permitirán la modernización de nuestro sistema fiscal haciéndolo más eficiente.

El primer bloque se concreta en la reciente aprobación de la Ley 11/2021, de 9 de julio, de medidas de prevención y lucha contra el fraude fiscal. Entre las medidas concretas para atajar el fraude incluidas en esta Ley se encuentra la prohibición del 'software de doble uso', como se denomina a los productos informáticos que permiten la ocultación de ventas y la manipulación de los estados contables.

Desde que en octubre de 2014 la OCDE publicara su trabajo "Tax Compliance by Design" (Cumplimento tributario por diseño), la idea de integración de sistemas informáticos de gestión empresarial y contable con los sistemas de captación y suministro de las Administraciones Tributarias viene siendo una constante en el desarrollo de las relaciones administración-administrado. La filosofía de esta tendencia consiste en evitar rupturas en la secuencia que va entre la generación del dato y su traslado a las autoridades competentes para conocerlo. No hay que decir que esta solución permite tanto una simplificación de procesos, ahorro de tiempo y eficiencia, a la vez que evita errores y dificulta el fraude. 
Para solventar en la medida de lo posible este tipo de fraude, la Organización para la Cooperación y el Desarrollo Económicos (OCDE), en su documento «Supresión electrónica de ventas: una amenaza para los ingresos fiscales» (2013) recomienda a las administraciones fiscales la implementación de soluciones tecnológicas efectivas. Por ello la estrategia a medio plazo de la Agencia Tributaria pasa por impulsar estas soluciones tecnológicas. Todo ello en permanente diálogo con las organizaciones representativas de autónomos y PYMES.

El segundo bloque de medidas tributarias se orienta a la modernización de la Agencia Tributaria, en especial en el ámbito digital.

En este contexto, las áreas de reforma contempladas desde el punto de vista gestor incluyen las siguientes:

\section{- Modernización informática de la gestión tributaria}

Entre los proyectos trazados en este ámbito destaca la optimización y racionalización de los recursos tecnológicos de la Agencia Tributaria, Tribunales Económicoadministrativos y Dirección General de Tributos, mediante el uso compartido de plataformas digitales comunes.

Asimismo, cabe resaltar las inversiones necesarias para hacer efectivas las medidas organizativas y operativas orientadas a incrementar la eficacia de la Administración Tributaria en el control tributario, pues la globalización de la economía y los nuevos modelos de negocio exigen de la Administración Tributaria un esfuerzo permanente de adaptación a la nueva realidad y necesidades, como por ejemplo para una mejor utilización de la información que obtiene mediante el Sistema de Suministro Inmediato de Información y la procedente del "Common Reporting Standard". También puede citarse como ejemplo el incremento creciente de la eficacia en el control de los grandes patrimonios que se está logrando gracias a la creación de la Unidad Central de Coordinación del Control de Patrimonios Relevantes y las nuevas herramientas de selección.

\section{- Mejoras en la selección para detectar ingresos no declarados}

Las actuaciones de la Agencia Tributaria se orientan hacia el análisis patrimonial y societario y la ocultación de actividad y abuso de formas societarias, con la finalidad de detectar aquellos incumplimientos más flagrantes, consistentes en ocultar la realización de hechos y bases imponibles a la Administración.

Estas actuaciones se enmarcan en una estrategia país para reducir la brecha fiscal y la economía sumergida.

Por una parte, en colaboración con las asociaciones representativas de PYMES y autónomos, se analizarán medidas tanto en el ámbito regulatorio de los distintos impuestos como en materia de obligaciones formales, todo ello en aras de facilitar el 
cumplimiento voluntario y asegurar la trazabilidad y el adecuado reflejo de las operaciones en los libros fiscales y en la contabilidad, minimizando el riesgo de ocultación de transacciones e ingresos, reduciendo, de esta manera, la brecha fiscal y la economía sumergida. Para alcanzar estos objetivos, las herramientas tecnológicas y la digitalización constituirán el eje de apoyo.

Por otra, se reforzarán las líneas de colaboración en esta estrategia país con las restantes Administraciones tributarias (autonómicas y locales), con la Seguridad Social y con la Inspección de Trabajo.

La combinación de datos fiscales y de los registros de la seguridad social, junto con la utilización de técnicas predictivas y de minería de datos permitirá reducir las bolsas de economía sumergida en el ámbito del autoempleo y de las micro empresas.

El tercer bloque pivota sobre Potenciación de la asistencia al contribuyente, área que constituye uno de los pilares del Plan Estratégico de la Agencia Tributaria en el período 2020-2023, y que tiene como proyecto emblemático la implantación de un nuevo modelo de asistencia integral en la Agencia Tributaria a través de la Administración Digital Integral (ADI).

\section{La nueva Administración Digital Integral ('ADI')}

La Agencia Tributaria ha puesto en servicio la nueva Administración Digital Integral ('ADI'), un 'mostrador virtual' diseñado bajo la premisa de facilitar el cumplimiento voluntario con más y mejor información y asistencia al contribuyente por parte de una Administración Tributaria más ágil, dinámica y cercana.

Complementando la ayuda presencial tradicionalmente prestada en las oficinas físicas, que continuará como hasta ahora, desde la ADI funcionarios especializados se dedican en exclusiva a atender de forma personalizada no presencial a contribuyentes de todo el territorio nacional. Irá desplegando paulatinamente sus servicios de información y asistencia, y contará, cuando finalice su implantación, con cuatro sedes: Valencia, Madrid, Galicia y Andalucía.

La ADI ofrece su servicio de ayuda a un amplio colectivo de beneficiarios potenciales -entre los que destacan emprendedores que inician su actividad, autónomos y pymes, arrendadores y profesionales tributarios, así como contribuyentes que necesiten asistencia para la tramitación de procedimientos tributarios-, con más amplitud de horario que las oficinas convencionales y evitando al ciudadano desplazamientos innecesarios.

La creación de la $A D I$, uno de los principales proyectos del Plan Estratégico de la Agencia 2020-2023, surge de la posibilidad que hoy en día ofrecen las nuevas tecnologías para aunar lo mejor de los dos grandes vectores tradicionales de asistencia al contribuyente, a los cuales la ADI complementa a partir de ahora: la habitual ayuda presencial y la alternativa telemática de autoservicio de calidad. 


\section{Un sistema multicanal integrado}

La Administración Digital Integral es multicanal, superando el concepto tradicional de asistencia personalizada mediante centros de atención telefónica. Para prestar su servicio, cuenta con las distintas herramientas telemáticas que ofrece la tecnología actual, desde asistentes virtuales hasta chats instantáneos $\boldsymbol{y}$ videollamadas, pasando por el teléfono tradicional y el 'click to call' (botón de llamada en la web), entre otros canales. La utilización de una u otra herramienta, o de varias de ellas consecutivamente, dependerá de cada servicio y trámite, y del grado de identificación electrónica requerido en cada caso.

Además, se implanta también un modelo integrado de acceso a los servicios que ofrece la Agencia Tributaria, ya que la ayuda que ofrece la ADI se incardina con el resto de funcionalidades y trámites que realiza la Administración Tributaria.

Así, un contribuyente que inicialmente tiene una duda en materia de IVA, o que solicita información sobre una notificación recibida, puede recibir la ayuda de la ADI para presentar una declaración o para dar respuesta al requerimiento de la Administración, solventando el trámite pendiente de una sola vez y evitándose tiempo y desplazamientos a la oficina de la Agencia, dado que se replica a distancia el funcionamiento de un mostrador físico tradicional.

\section{Las ventajas del mostrador virtual}

Junto con la facilidad y comodidad de acceso para el contribuyente por no tener que acudir físicamente a la oficina, la ADI ofrece un horario ampliado, de 9 a 19 horas, que duplica al que se dedica a la atención al público en las oficinas físicas.

Por otra parte, y al contar con personal especializado y exclusivamente dedicado a la asistencia, se refuerza la homogeneidad y la calidad del servicio al contribuyente, lo que favorece, a su vez, la unidad de criterio en la aplicación de la norma tributaria y, con ello, la seguridad jurídica.

\section{¿Cómo funciona y qué servicios presta?}

La integración de la Administración Digital Integral con los distintos trámites y servicios de la Agencia se traduce en que el contribuyente, en una gran variedad de supuestos, solicitará la ayuda ante una situación concreta que se le está dando en vivo, en ese momento.

Sería, por ejemplo, el caso de un contribuyente que se encuentra con dificultades para presentar una declaración trimestral de IVA y se le ofrece la posibilidad de ayudarle en la presentación, o que ha recibido una notificación de la Agencia que incluye un teléfono para el caso de que necesite aclaraciones.

También los distintos asistentes virtuales existentes en materia de IVA y censos son un canal de acceso a la ADI, de tal manera que el sistema puede detectar dificultades 
(repetición de errores, o un tiempo prolongado de uso de la herramienta) y, automáticamente, al contribuyente le aparece un ofrecimiento de ayuda mediante el sistema de chat instantáneo.

El tipo de ayuda se divide en dos partes, la información, para los casos en que el contribuyente únicamente necesita consultar cómo tributa una operación, qué trámite debe realizar en un determinado supuesto, etc. y la asistencia para presentar una declaración, o para responder a un procedimiento iniciado por la Agencia.

En el ámbito de la información, entre otros servicios la ADI resuelve inicialmente dudas sobre IVA, altas, modificaciones y bajas de actividad, y también sobre notificaciones que ha recibido el contribuyente.

A su vez, en el ámbito de la asistencia se facilita la presentación de declaraciones censales, trimestrales de IVA para arrendadores y para autónomos y pymes que inicien su actividad, y trimestrales de contribuyentes en módulos y declaraciones complementarias de IRPF de años anteriores, así como, en materia aduanera, declaraciones simplificadas de importación y devoluciones de gasóleo agrícola y profesional. A lo largo del presente año se ampliará la asistencia a otros servicios, como la ayuda a la presentación de declaraciones complementarias de IRPF.

La ADI también ofrece un nuevo producto, denominado 'Informa+', que consiste en la solicitud, por parte del contribuyente, de una respuesta por escrito a su consulta, de forma que pueda tener certeza jurídica sobre el tratamiento tributario de una determinada operación económica que prevé realizar.

Tras el arranque en Valencia con información y asistencia en IVA, módulos, trámites censales y las gestiones aduaneras más habituales; y en Madrid con ciertos controles de IRPF, a lo largo de 2021 se incorporará la sede de Galicia, a la que seguirá la de Andalucía en 2022.

\section{Novedades en Tecnologías de la Información y las Comunicaciones}

Las novedades sobre nuevos usos de tecnologías en el ámbito de los servicios públicos $y$, en particular, de la administración tributaria, se suceden continuamente y se han visto impulsados en mayor medida por las condiciones de teletrabajo durante la pandemia. La ampliación de usos de algunos servicios de registro electrónico, la aparición y consolidación de otros novedosos, como el registro en el servicio de identificación cl@ve por video-asistencia, así como la creación de administraciones digitales integradas, con relaciones con los contribuyentes a distancia multicanal, se han visto impulsadas decididamente durante los últimos 18 meses. A todos estos servicios podemos añadir, entre otros, la novedad reciente en el ámbito de las notificaciones electrónicas con la creación y puesta en marcha de la Dirección Electrónica Habilitada única (DEHú) como elemento unificador de los procesos de notificación electrónica o la nueva sede electrónica de la Agencia Tributaria. Por último, en la pasada campaña de Renta 2020 se mantuvo la asistencia telefónica con el Plan "Le Llamamos", que ya comenzara en 2019 con gran aceptación, pero que en la campaña de renta de este año ha tenido en el programa de ayuda RENTAWEB una 
de las novedades tecnológicas más novedosas, introduciendo el BIG DATA en el control de errores y asistencia a los ciudadanos a la hora de cumplimentar su declaración.

\subsection{Video-asistencia en servicios de acreditación de la identidad}

En diferentes servicios prestados a distancia por entidades financieras y otros organismos, se han comenzado a usar mecanismos de visualización de imágenes a distancia para sustituir la presencia física de los ciudadanos en las oficinas. La apertura de cuentas corrientes en algunos bancos ya se puede realizar mediante la captación de imágenes biométricas de la cara y de la documentación aportada o "mostrada" a la cámara. En la AEAT se lleva desde el año 2020 realizando la acreditación de la identidad para el registro en el sistema de identificación CI@vePIN mediante video-

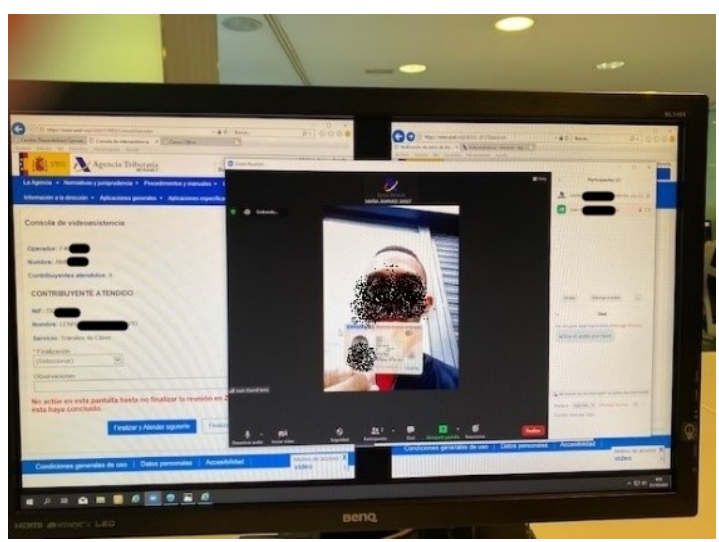
asistencia online de la imagen y la voz del ciudadano y la voz del empleado público. Hasta el comienzo de este servicio, se requería la solicitud de cita previa, presencia física del ciudadano en los mostradores de las oficinas de la AEAT para mostrar el DNI y efectuar el registro del móvil en la aplicación correspondiente. Mediante la video-asistencia ahorramos tiempo y desplazamientos innecesarios. El sistema es sencillo y se basa en el uso de una herramienta colaborativa (cuyo uso se

ha generalizado durante la pandemia) para iniciar una sesión de video-audio y poner en comunicación al funcionario y ciudadano. Mediante la grabación de la conversación se registra la voluntad del ciudadano y mediante la imagen en vivo se revisa la documentación para la identificación y se comprueba la imagen del ciudadano. El envío de un SMS al móvil registrado permite remitir en el momento el resguardo del trámite al ciudadano con el CSV correspondiente.

En el tiempo que lleva el sistema en marcha (algo más de 1 año) se han efectuado alrededor de 600.000 registros de alta en el sistema Cl@vePIN mediante videoasistencia, muchos de ellos a ciudadanos desplazados en el extranjero. El acceso está disponible en el apartado de la Sede de la AEAT: Acceda directamente $\rightarrow$ Identificación digital.

El siguiente servicio a la vista es permitir la video-asistencia en la identificación de las personas físicas en la fase de acreditación para la obtención de certificados electrónicos cualificados de persona física. La regulación técnica ya se ha publicado en el BOE mediante la Orden TD/465/2021, de 6 de mayo, por la que se regulan los métodos de identificación remota por vídeo para la expedición de certificados electrónicos cualificados. Esta orden fija los criterios y condiciones mínimas para la identificación por video-asistencia de acuerdo a lo previsto en el Reglamento (UE) 910/2014, del Parlamento Europeo y del Consejo, de 23 de julio de 2014 y en la Ley $6 / 2021$ de 11 de noviembre por la que se regulan determinados aspectos de los servicios electrónicos de confianza. 


\subsection{Avisos en la ayuda para la confección de la Renta a través de RENTAWEB}

El uso de avisos, recordatorios o recomendaciones ha sido utilizado frecuentemente por los organismos tributarios de muchos países, por ejemplo, el HMRC en el Reino Unido. Se basa en adelantar al contribuyente información que ya conoce la administración tributaria para promover la presentación completa y correcta de las declaraciones fiscales. Si bien en España llevamos ya muchos años enviando datos fiscales y borradores a los contribuyentes con carácter previo a la declaración de la Renta, sólo desde hace relativamente poco tiempo la AEAT ha comenzado a enviar cartas o avisos. En esta pasada campaña de Renta 2020 se ha dado un paso más y se ha efectuado una adaptación del programa RENTAWEB para incorporar estos avisos previendo o anticipando posibles errores del contribuyente.

La Agencia tributaria realiza con posterioridad a las campañas de renta un análisis completo de las declaraciones y los errores cometidos. Dispone de gran volumen de información, casi 22 millones de declaraciones, un repositorio completo de datos estructurados, numéricos y de calidad, lo cual permite efectuar análisis de datos $\boldsymbol{y}$ perfiles de contribuyentes para aplicar técnicas de BIG DATA e Inteligencia Artificial. Aplicando técnicas de Machine Learning se analizaron los datos de Renta 2019 y las modificaciones que los contribuyentes realizaron de partidas pre-rellenas con la información de los datos fiscales del contribuyente y cuya modificación por el contribuyente supuso sin embargo un error o descuadre en la declaración. Es decir, se observaron comportamientos del siguiente tipo: el programa Rentaweb ofrece la partida de la declaración cumplimentada con los datos fiscales, el contribuyente la modifica según su criterio, el resultado es una declaración presentada y formalmente correcta en la que, sin embargo, las verificaciones y controles de riesgos que efectúa la AEAT tras la recepción telemática de la declaración detectan un posible error que puede derivar en un requerimiento o una regularización tributaria. Como hemos indicado anteriormente, este escenario permite definir modelos de datos y análisis supervisados del tipo: Datos $\rightarrow$ Acción $\rightarrow$ Error o Éxito. Del estudio y análisis de los 22 millones de declaraciones de 2019 se detectaron las modificaciones de partidas que más errores suponían (se seleccionaron 6 de ellas) y esas se incorporaron al programa Rentaweb de 2020 en forma de avisos que se activaban en el momento que el contribuyente pretendía modificarlas. En definitiva, el contribuyente recibe un sencillo mensaje de "¿Está usted seguro de que quiere modificar esta partida?" en el que en realidad subyace un trabajo de análisis de información muy complejo. Como elemento final de esta nueva metodología de control de errores, se analizará la eficacia de estos avisos, comparando los errores en IRPF 2020 frente a los de 2019 en la información referida a estas partidas.

\subsection{La nueva Dirección Electrónica Habilitada Única (DEHú)}

A partir del 6 de septiembre de 2021, todas las notificaciones y comunicaciones de la

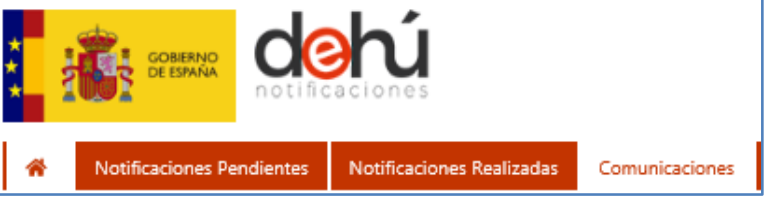
Agencia Tributaria estarán disponibles en la Dirección Electrónica Habilitada única (en adelante DEHú). Se establece un periodo transitorio donde se publicarán simultáneamente en la 
DEH y en la DEHú, además de en la Sede Electrónica de la AEAT. La DEH era el repositorio de Notificaciones utilizado por muchos organismos, entre ellos la AEAT, que en un periodo de tiempo desaparecerá sustituido por la DEHú.

El Real Decreto 203/2021, de 30 de marzo, en el artículo 42 sobre la práctica de las notificaciones a través de medios electrónicos establece en el punto 5: "Toda notificación cuyo emisor pertenezca al ámbito estatal a que se refiere el artículo 1.2 de este Reglamento se pondrá a disposición del interesado a través de la Dirección Electrónica Habilitada única, incluyendo el supuesto previsto en el artículo 42.1 de la Ley 39/2015, de 1 de octubre. Asimismo, los emisores de ámbito estatal podrán notificar en su sede electrónica o sede electrónica asociada de forma complementaria a la puesta a disposición en la Dirección Electrónica Habilitada única."

A la DEH se envían para comparecer únicamente las notificaciones electrónicas. A la DEHú se enviarán todas las notificaciones, tal como se está haciendo actualmente en la Sede electrónica y en Carpeta Ciudadana. Se tendrá acceso a las notificaciones depositadas por la Agencia Tributaria en la DEHú por dos vías:

- A través del portal https://DEHú.redsara.es/, autenticándose con certificado electrónico o Cl@vePIN.

- A través de servicios web para la descarga masiva de notificaciones. Este servicio, orientado a grandes receptores de comunicaciones y notificaciones administrativas, permite una gestión completa de todas las notificaciones procedentes de los diversos organismos públicos.

Dos aspectos son de interés: la DEHú mantiene el sistema de avisos de notificaciones recibidas por correo electrónico que ya disponía la DEH y en los que se comunica información de la notificación tal como organismo emisor y datos de tramitación y estado de la misma. Actualmente, con las configuraciones adecuadas, pueden recibirse correos de aviso de puesta a disposición desde tres orígenes: Agencia Tributaria@correo.aeat.es, norepli.DEHú@correo.gob.es_y notificaciones.sne@fnmt.es. Por otra parte, las notificaciones pueden recibirse en diversos buzones electrónicos y, aunque existe coordinación entre ellos, es posible la comparecencia de la notificación en más de uno de ellos, teniendo prioridad y vigencia la fecha y hora de la primera que se hubiera efectuado.

\section{Conclusiones}

En la actualidad, los sistemas de análisis de información cobran una importancia creciente. En los próximos años la Agencia Tributaria aprovechará el potencial que ofrece la tecnología para culminar el proceso de automatización en la tramitación de procedimientos iniciado hace años. De esta forma se liberarán recursos humanos para las actividades de mayor valor añadido, se garantizará un tratamiento uniforme a los contribuyentes, se podrá facilitar el cumplimiento de sus obligaciones y contribuir a erradicar el fraude fiscal. Para ello serán claves las nuevas tecnologías como el tratamiento del lenguaje natural, el tratamiento avanzado de datos y la inteligencia artificial. 